\title{
Flat crown ethers with planar tetracoordinate carbon atoms
}

\author{
Venkatesan S. Thimmakondu, ${ }^{\dagger} \quad$ Krishnan Thirumoorthy ${ }^{\ddagger}$
}

\begin{abstract}
Novel flat crown ether molecules have been characterized in silico using DFT hybrid and hybrid-meta functionals. Monomer units of $\mathrm{Si}_{2} \mathrm{C}_{3}$ with a planar tetracoordinate carbon atom have been used as building blocks. Alkali $\left(\mathrm{Li}^{+}, \mathrm{Na}^{+}, \mathrm{K}^{+}, \mathrm{Rb}^{+}\right.$, and $\left.\mathrm{Cs}^{+}\right)$and alkaline-earth $\left(\mathrm{Ca}^{2+}, \mathrm{Sr}^{2+}\right.$, and $\left.\mathrm{Ba}^{2+}\right)$ metals, and uranyl $\left(\mathrm{UO}_{2}^{2+}\right)$ ion selective complexes have also been theoretically identified. The high symmetry and higher structural rigidity of the host molecules may likely to impart higher selectivity in chelation. Theoretical binding energies have been computed and experimental studies are invited.
\end{abstract}

\footnotetext{
* corresponding author

${ }^{\dagger}$ Department of Chemistry and Biochemistry, San Diego State University, San Diego, CA 92182-1030, USA. E-mail: vthimmakondusamy@sdsu.edu

${ }^{\ddagger}$ Department of Chemistry, School of Advanced Sciences, Vellore Institute of Technology, Vellore - 632 014, Tamil Nadu, India
} 


\section{Introduction}

The concept of molecules with a planar tetracoordinate carbon $(\mathrm{ptC})^{1,2}$ atom is an inspiration to all chemists despite it breaks one of the fundamental paradigms of organic chemistry - i.e., tetrahedral tetracoordinate carbon. ${ }^{3-14}$ Experimental and theoretical confirmation of pentaatomic ptC species $\left(\mathrm{CAl}_{4}^{-}, \mathrm{CAl}_{3} \mathrm{Si}^{-/ 0}\right.$, $\mathrm{CAl}_{3} \mathrm{Ge}^{-/ 0}, \mathrm{CAl}_{4}^{2-}$, etc., ${ }^{15-18}$ have given some momentum in the search of these molecules in the gas phase. Stabilization of ptC by hydrogenation, in the case of $\mathrm{CAl}_{4} \mathrm{H}^{-/ 0}$, has also been reported recently. ${ }^{19}$ The effect of "pt" silicon $(\mathrm{ptSi})^{20-24}$ atom in the stability of calix[4]pyrrole hydridosilicate ${ }^{25}$ serves as the first experimental proof for ptSi, which motivates the study of these molecules further. Experimentally, it was also demonstrated in the past that molecules with a ptC atom can be enormously stabilized by the cooperative influence of metal pairs $\left(\mathrm{Zr} / \mathrm{Al}\right.$ or $\left.\mathrm{Zr} / \mathrm{Zr}^{+}\right)$of atoms. ${ }^{26}$ The first crystallographically characterized ptC molecule, a divanadium complex, identified by Cotton and Miller, ${ }^{27}$ was recognized later by Keese. ${ }^{4}$ It is also noted here that molecules with a planar hypercoordinate carbon (phC) ${ }^{7,28-38}$ atom are also actively pursued. Apart from the chemical bonding perspective, interest in molecules with a $\mathrm{ptC}$ or $\mathrm{phC}$ atom stems from the fact that they could be used as potential new materials. ${ }^{21,39}$

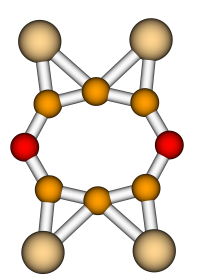

(a) $\mathrm{Si}_{2} \mathrm{C}_{3}$-8-crown-2 $\left(D_{2 h}\right)$

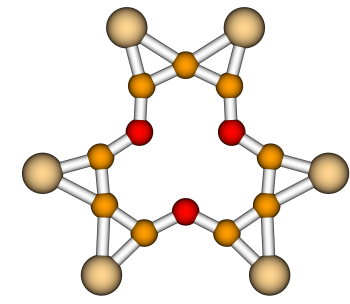

(b) $\mathrm{Si}_{2} \mathrm{C}_{3}-12$-crown-3 $\left(D_{3 h}\right)$

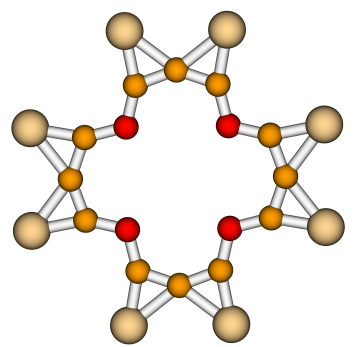

(c) $\mathrm{Si}_{2} \mathrm{C}_{3}$-16-crown-4 $\left(D_{4 h}\right)$

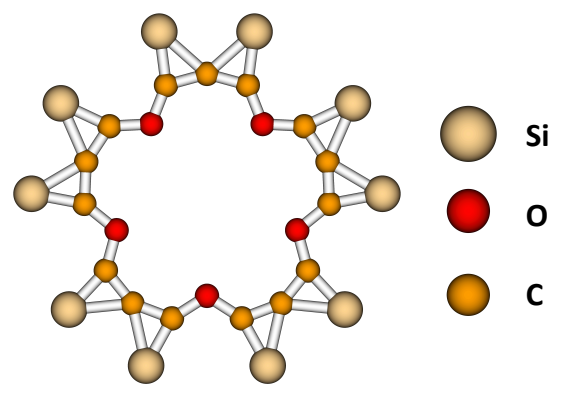

(d) $\mathrm{Si}_{2} \mathrm{C}_{3}-20$-crown-5 $\left(D_{5 h}\right)$

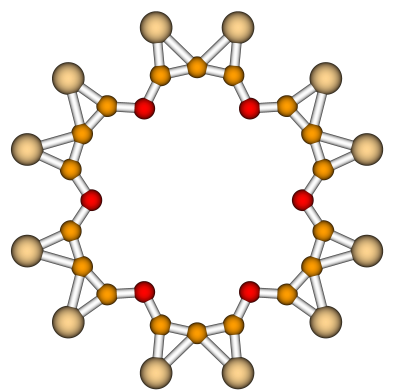

(e) $\mathrm{Si}_{2} \mathrm{C}_{3}$-24-crown-6 $\left(D_{6 h}\right)$

Figure 1: Flat crown ethers of $\mathrm{Si}_{2} \mathrm{C}_{3}$ with ptC atoms identified at the B3LYPD3BJ $/ 6-311++\mathrm{G}(2 \mathrm{~d}, 2 \mathrm{p})$ level of theory. 
Pioneering work on crown ethers by Pedersen ${ }^{40}$ and Cram, ${ }^{41}$ and on cryptands by Lehn ${ }^{42}$ marked the birth of a new field called supramolecular chemistry. Whether it is a liquid or gas phase, conventional crown ether molecules characteristically bind different metal cations depending upon the size of the macrocyclic ring, polarity of the medium, and also the type of the donor atom. ${ }^{43-45}$ Because of this versatility, more than 10,000 crown ether molecules have been synthetically characterized ${ }^{46-50}$ and their potential applications in phase transfer catalysis, ${ }^{51}$ chemical separations, ${ }^{52}$ analytical methods, ${ }^{53}$ and also in nuclear waste management have already been well-documented. ${ }^{54-56}$ Motivated by molecules with a ptC atom and also by crown ethers, new "flat crown ether molecules" have been designed here and their chelation behavior have also been explored computationally. Embedding crown ethers in graphene ${ }^{57}$ or carbon nanostructures ${ }^{58}$ have been emerging to control their low structural rigidity. ${ }^{59-61}$ Preorganizing the host molecule to suit the guest is a necessity for its potential applications. Here, instead of using a graphene environment, a novel approach has been followed by taking advantage of the concept of molecules with a ptC atom and consequentially making flat crown ethers to maximize its suitability.

\section{Results and Discussion}

In this work, utilizing $\mathrm{Si}_{2} \mathrm{C}_{3}$ with a ptC atom as a base unit, we have computationally identified different flat crown ethers starting from $\mathrm{Si}_{2} \mathrm{C}_{3}$-8-crown$2\left(\mathrm{Si}_{2} \mathrm{C}_{3}-8 \mathrm{C} 2\right.$ from here on wards) to $\mathrm{Si}_{2} \mathrm{C}_{3}$-24-crown-6 $\left(\mathrm{Si}_{2} \mathrm{C}_{3}-24 \mathrm{C} 6\right)$, which are depicted in Figure 1. Five different flat metal-chelated complexes identified at the B3LYP-D3BJ/6-311++G(2d,2p) level of theory, $\mathrm{Li}^{+}-\mathrm{Si}_{2} \mathrm{C}_{3}-16 \mathrm{C} 4$, $\mathrm{Na}^{+}-\mathrm{Si}_{2} \mathrm{C}_{3}-16 \mathrm{C} 4, \mathrm{Ca}^{2+}{ }_{-} \mathrm{Si}_{2} \mathrm{C}_{3}-16 \mathrm{C} 4, \mathrm{~K}^{+}-\mathrm{Si}_{2} \mathrm{C}_{3}-20 \mathrm{C} 5$, and $\mathrm{Rb}^{+}-\mathrm{Si}_{2} \mathrm{C}_{3}-20 \mathrm{C} 5$ are shown in Figures 2 (a), (b), (c), (d), and (e), respectively. $\mathrm{Si}_{2} \mathrm{C}_{3}-16 \mathrm{C} 4$ also forms a coordinated complex with uranyl ion, $\mathrm{UO}_{2}^{2+}-\mathrm{Si}_{2} \mathrm{C}_{3}-16 \mathrm{C} 4$, which is shown in Figure 3. For brevity, all optimal geometry parameters collected are shown in the electronic supporting information and the binding energies computed for various metal-chelated $\mathrm{Si}_{2} \mathrm{C}_{3}$-flat crown ethers including $\mathrm{UO}_{2}^{2+}$ are given in Table 1. In this communication, predominant focus has been paid on $\mathrm{Si}_{2} \mathrm{C}_{3}-16 \mathrm{C} 4$ and $-20 \mathrm{C} 5$ and their chelated complexes considering the cavity ring sizes and ionic radii of different metal ions. Metal chelation studies with $\mathrm{Si}_{2} \mathrm{C}_{3}-24 \mathrm{C} 6$ is currently ongoing and would be the focus of our future work. Starting from $\mathrm{Si}_{2} \mathrm{C}_{3}-16 \mathrm{C} 4$, as the overall cavity ring size increases (especially diagonal O-O distances), alkali metal ions $\mathrm{Li}^{+}$and $\mathrm{Na}^{+}$, and alkaline-earth metal ion, $\mathrm{Ca}^{2+}{ }_{-}$ chelated complexes are possible and they have been identified to be minima using DFT at all levels employed herein. Although $\mathrm{K}^{+}$forms a complex with $\mathrm{Si}_{2} \mathrm{C}_{3}-16 \mathrm{C} 4$, flat structure was found to be a transition state and minimum geometry was found to be in a "quasi plate" shape (see Figure 4). Immediate higher homologue, $\mathrm{Si}_{2} \mathrm{C}_{3}-20 \mathrm{C} 5$, hosts both $\mathrm{K}^{+}$and $\mathrm{Rb}^{+}$and retains overall planarity.

From Table 1, the following trend has been observed. As the ionic radii 


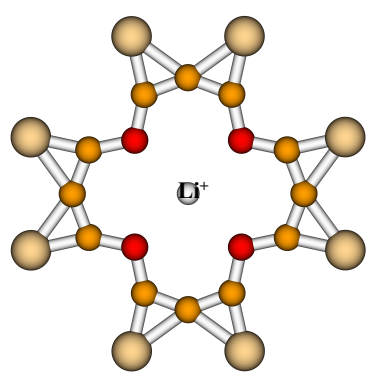

(a) $\mathrm{Li}^{+}-\mathrm{Si}_{2} \mathrm{C}_{3}-16-$ crown-4

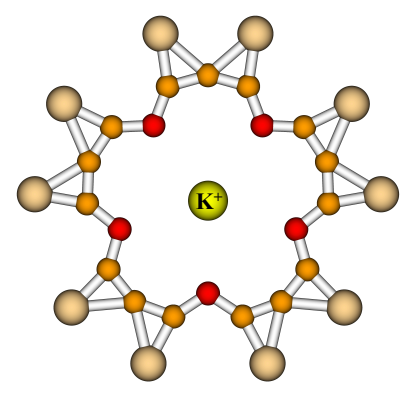

(d) $\mathrm{K}^{+}-\mathrm{Si}_{2} \mathrm{C}_{3}-20$-crown-5

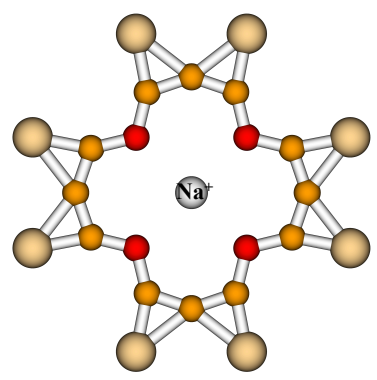

(b) $\mathrm{Na}^{+}-\mathrm{Si}_{2} \mathrm{C}_{3}-16$-crown-4

$\mathbf{M}^{+}-$-O distance $(\AA)$

(a) $\mathrm{Li}^{+}-\mathrm{-O}=\mathbf{2 . 2 0 3}$

(b) $\mathrm{Na}^{+}-\mathrm{O}=2.299$

(c) $\mathrm{Ca}^{2+}--\mathrm{O}=2.324$

(d) $\mathrm{K}^{+}-\mathrm{-O}=\mathbf{3 . 0 4 4}$

(e) $\mathrm{Rb}^{+}--\mathrm{O}=3.076$

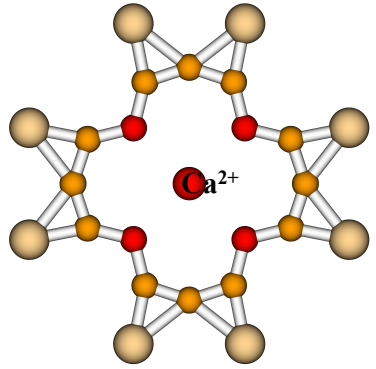

(c) $\mathrm{Ca}^{2+}-\mathrm{Si}_{2} \mathrm{C}_{3}-16$-crown-4

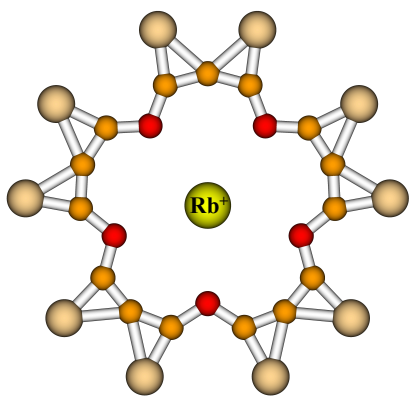

(e) $\mathrm{Rb}^{+}-\mathrm{Si}_{2} \mathrm{C}_{3}-20$-crown-5

Figure 2: Five different $\mathrm{M}^{+}$-chelated $\mathrm{Si}_{2} \mathrm{C}_{3}$ crown ethers identified at the B3LYP-D3BJ/6-311++G(2d,2p) level of theory.

Table 1: Binding energies (in eV) of flat $\mathrm{Si}_{2} \mathrm{C}_{3}$ metal-chelated crown ethers calculated at different levels.

\begin{tabular}{|c|c|c|c|c|c|c|}
\hline \multirow[t]{2}{*}{ Species } & \multirow{2}{*}{$\begin{array}{l}\text { Symmetry; } \\
\text { State }\end{array}$} & PBE0 & B3LYP & B3LYP-D3BJ & TPSSh & TPSSh-D3BJ \\
\hline & & \multicolumn{5}{|c|}{$6-311++\mathrm{G}(2 \mathrm{~d}, 2 \mathrm{p})$} \\
\hline $\mathrm{Li}^{+}-\mathrm{Si}_{2} \mathrm{C}_{3}-16 \mathrm{C} 4$ & ${ }^{1} A_{1 g} ; D_{4 h}$ & -3.22 & -3.44 & -3.80 & -3.16 & -3.43 \\
\hline $\mathrm{Na}^{+}-\mathrm{Si}_{2} \mathrm{C}_{3}-16 \mathrm{C} 4$ & ${ }^{1} A_{1 g} ; D_{4 h}$ & -2.51 & -2.75 & -3.16 & -2.46 & -2.74 \\
\hline $\mathrm{K}^{+}-\mathrm{Si}_{2} \mathrm{C}_{3}-16 \mathrm{C} 4^{a}$ & ${ }^{1} A_{1} ; C_{4 v}$ & -1.59 & -1.81 & -2.22 & -1.61 & -1.91 \\
\hline $\mathrm{Rb}^{+}-\mathrm{Si}_{2} \mathrm{C}_{3}-16 \mathrm{C}_{4}^{a}$ & ${ }^{1} A_{1} ; C_{4 v}$ & -1.19 & -1.37 & -1.78 & -1.20 & -1.51 \\
\hline $\mathrm{Cs}^{+}-\mathrm{Si}_{2} \mathrm{C}_{3}-16 \mathrm{C} 4^{a}$ & ${ }^{1} A_{1} ; C_{4 v}$ & -0.96 & -1.12 & -1.52 & -0.99 & -1.28 \\
\hline $\mathrm{Ca}^{2+}-\mathrm{Si}_{2} \mathrm{C}_{3}-16 \mathrm{C} 4$ & ${ }^{1} A_{1 g} ; D_{4 h}$ & -7.88 & -8.23 & -8.76 & -7.82 & -8.19 \\
\hline $\mathrm{Sr}^{2+}-\mathrm{Si}_{2} \mathrm{C}_{3}-16 \mathrm{C} 4^{a}$ & ${ }^{1} A_{1} ; C_{4 v}$ & -5.77 & -6.17 & -6.70 & -5.79 & -6.15 \\
\hline $\mathrm{Ba}^{2+}-\mathrm{Si}_{2} \mathrm{C}_{3}-16 \mathrm{C}^{a}$ & ${ }^{1} A_{1} ; C_{4 v}$ & -4.70 & -5.11 & -5.68 & -4.79 & -5.19 \\
\hline $\mathrm{K}^{+}-\mathrm{Si}_{2} \mathrm{C}_{3}-20 \mathrm{C} 5$ & ${ }^{1} A_{1}^{\prime} ; D_{5 h}$ & -1.92 & -2.08 & -2.54 & -1.86 & -2.21 \\
\hline $\mathrm{Rb}^{+}-\mathrm{Si}_{2} \mathrm{C}_{3}-20 \mathrm{C} 5$ & ${ }^{1} A_{1}^{\prime} ; D_{5 h}$ & -1.62 & -1.82 & -2.31 & -1.61 & -1.97 \\
\hline $\mathrm{Cs}^{+}-\mathrm{Si}_{2} \mathrm{C}_{3}-20 \mathrm{C} 5^{a}$ & ${ }^{1} A_{1} ; C_{5 v}$ & -1.32 & -1.51 & -1.99 & -1.33 & -1.68 \\
\hline$\left[\mathrm{UO}_{2}-\mathrm{Si}_{2} \mathrm{C}_{3}-16 \mathrm{C} 4\right]^{2+}$ & ${ }^{1} A_{1 g} ; D_{4 h}$ & -9.02 & -9.39 & -10.33 & -9.28 & -9.95 \\
\hline
\end{tabular}

${ }^{a}$ This $\mathrm{M}^{+}$-chelated structure is not completely flat.

increases down the group, binding energy decreases. While $\mathrm{Li}^{+}$and $\mathrm{Na}^{+}$make a chelated complex with $\mathrm{Si}_{2} \mathrm{C}_{3}-16 \mathrm{C} 4$ and retains planarity, $\mathrm{K}^{+}, \mathrm{Rb}^{+}$, and $\mathrm{Cs}^{+}$ do not maintain planarity in minimum energy geometries though binding occurs. This is not surprising due to the fact that ionic radii increases further 
from $\mathrm{Na}^{+}$to $\mathrm{K}^{+}$. However, due to higher structural rigidity, the host molecule is unable to accommodate $\mathrm{K}^{+}$ion inside the cage (see Figure 4). Consequently, the electrostatic interactions between $\mathrm{K}^{+}$and four oxygen atoms push the entire molecule like a "quasi plate". Similar structures have been obtained for $\mathrm{Rb}^{+}$ and $\mathrm{Cs}^{+}$in chelation with $\mathrm{Si}_{2} \mathrm{C}_{3}-16 \mathrm{C} 4$ (not shown here for brevity). Moving to higher homologue, $\mathrm{Si}_{2} \mathrm{C}_{3}-20 \mathrm{C} 5$, when $\mathrm{Li}^{+}$and $\mathrm{Na}^{+}$ions remain at the center, they become higher-order saddle points (see supporting information for details). However, $\mathrm{K}^{+}$binds with this host molecule (see Figure 2) due to slightly increased ring size now and the binding energies are in the range of -1.86 to -2.54 $\mathrm{eV}$. Perhaps, though there are five oxygen donor atoms now, the binding energy is still slightly larger $(-2.54 \mathrm{eV})$ compared to the lower homologue $(-2.22$ $\mathrm{eV})$ at the same level of theory (B3LYP-D3BJ/6-311++G(2d,2p); see Table 1). Indirectly, this feature imposes higher selectivity. Also, this indicates that the electrostatic interactions are stronger when planarity is maintained. $\mathrm{Rb}^{+}$also binds with $\mathrm{Si}_{2} \mathrm{C}_{3}-20 \mathrm{C} 5$. Here, it maintains planarity unlike $\mathrm{Rb}^{+}-\mathrm{Si}_{2} \mathrm{C}_{3}-16 \mathrm{C} 4$. The binding energies are in the range of -1.61 to $-2.31 \mathrm{eV}$ for $\mathrm{Rb}^{+}-\mathrm{Si}_{2} \mathrm{C}_{3}-20 \mathrm{C} 5$. Just like $\mathrm{K}^{+}$ion, binding energies are slightly larger for $\mathrm{Rb}^{+}$(despite 5 donor atoms now instead of 4) when the entire molecule is in one plane. With $\mathrm{Cs}^{+}$, binding occurs with $\mathrm{Si}_{2} \mathrm{C}_{3}-20 \mathrm{C} 5$ but planarity is no longer maintained.

As far as alkali-earth metals are concerned, when $\mathrm{Be}^{2+}$ remains at the center in $\mathrm{Si}_{2} \mathrm{C}_{3}-16 \mathrm{C} 4$, all the calculations at different levels lead to multiple number of imaginary frequencies. On the contrary, $\mathrm{Mg}^{2+}$ with $\mathrm{Si}_{2} \mathrm{C}_{3}-16 \mathrm{C} 4$ makes covalent bonds with oxygen atoms but that geometry eventually turned out to be a second-order saddle point at all levels (see supporting information). However, the next ion $\mathrm{Ca}^{2+}$, whose ionic radii (114 pm) is comparable to $\mathrm{Na}^{+}$(116 pm), binds with $\mathrm{Si}_{2} \mathrm{C}_{3}-16 \mathrm{C} 4$. Due to higher charge and also being in planar configuration, the binding energies are sufficiently high (-7.82 to $-8.76 \mathrm{eV}$; see Table 1) for $\mathrm{Ca}^{2+}-\mathrm{Si}_{2} \mathrm{C}_{3}-16 \mathrm{C} 4 . \mathrm{Sr}^{2+}$ and $\mathrm{Ba}^{2+}$ also bind with the latter, however, planarity is lost yet again due to increased ionic radii. Also, their binding energies are comparably less compared to $\mathrm{Ca}^{2+}$. Our investigation is currently ongoing with respect to binding tendencies of alkali-earth metal ions in $\mathrm{Si}_{2} \mathrm{C}_{3}-20 \mathrm{C} 5$. It is noted here that $\mathrm{Si}_{2} \mathrm{C}_{3}-16 \mathrm{C} 4$ also forms a complex with uranyl ion, $\left[\mathrm{UO}_{2}-\mathrm{Si}_{2} \mathrm{C}_{3^{-}}\right.$ $16 \mathrm{C} 4]^{2+}$ (see Figure 3). The reason we had tried this particular ion is largely due to the fact that enormous amount of effort had already been devoted in making new chelating agents for $\mathrm{UO}_{2}^{2+62,63}$. into uranyl oxides. Here, we are proposing a new chelating agent for $\mathrm{UO}_{2}^{2+}$ whose binding energies are in the range of -9.02 to $-10.33 \mathrm{eV}$.

The optimal geometry parameters of various flat crown ethers are collected in the ESI†. The ptC-C and ptC-Si bond lengths show single bond characteristics. Also, quite consistently, the $\mathrm{Si}-\mathrm{C}$ bond length exhibits double bond characteristics $(\sim 1.75 \AA)$ in all cases. The optimized geometries of neutral flat crown ethers and their chelated complexes identified here are of same symmetry when planarity is maintained. In all cases, the ground electronic states are singlets and they are non-degenerate. Thus, they are not Jahn-Teller distorted ${ }^{64}$ within their ground electronic states. 


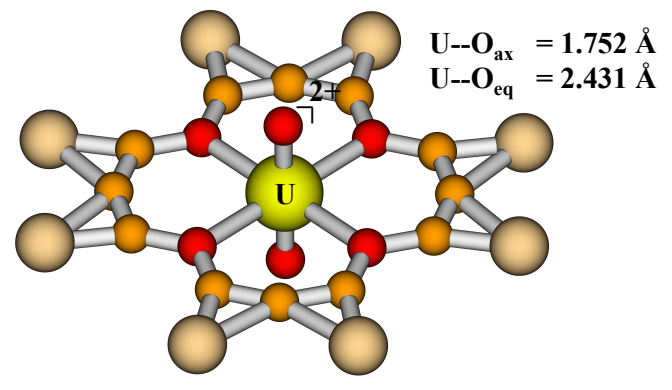

Figure 3: $\quad\left[\mathrm{UO}_{2}-\mathrm{Si}_{2} \mathrm{C}_{3}-16 \text {-crown-4 }\right]^{2+}$ identified at the B3LYP-D3BJ/6$311++\mathrm{G}(2 \mathrm{~d}, 2 \mathrm{p})$ level of theory.
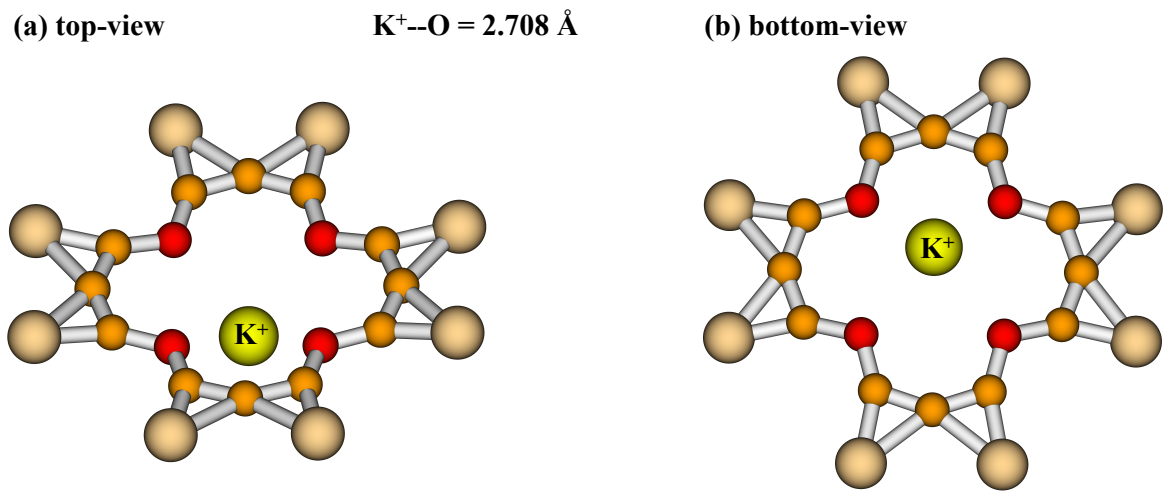

Figure 4: Two different views of $\mathrm{K}^{+}-\mathrm{Si}_{2} \mathrm{C}_{3}-16$-crown-4 identified at the B3LYPD3BJ $/ 6-311++\mathrm{G}(2 \mathrm{~d}, 2 \mathrm{p})$ level of theory are shown. 


\section{Conclusions}

In conclusion, a new series of crown ether molecules called "flat crown ethers" have been computationally characterized using the advent of molecules with a ptC atom. This novel approach opens up a new direction in the area of already popular "supramolecular chemistry". The synthetic possibilities of these molecules are invited and there are ample amount of reasons why one should study these molecules considering their higher degree of selectivity in metal chelation and also symmetry. Chelation with $\mathrm{UO}_{2}^{2+}$ is certainly encouraging to study these molecules further. Perhaps, only time shall tell what kind of potential applications or further new avenues are possible with these peculiar molecules.

\section{Computational Details}

Initially geometry optimization and frequency calculations have been done using density functional theory (DFT) with two different hybrid-functionals, PBE0 ${ }^{65}$ and B3LYP ${ }^{66-68}$ with the $6-311++\mathrm{G}(2 \mathrm{~d}, 2 \mathrm{p})$ basis set. ${ }^{69,70}$ All minima obtained at these latter levels have been reoptimized including Grimme's empirical dispersion corrections (D3) ${ }^{71}$ with Becke-Johnson damping (D3BJ) ${ }^{72,73}$ to make sure whether the wavefunction is stable or not. Further, all geometries have also been optimized with the TPSSh ${ }^{74}$ hybrid-meta functional including D3BJ corrections. All the flat crown ethers studied here are found to be stable at these five different levels of theory. For $\mathrm{Rb}^{+}-, \mathrm{Cs}^{+}-, \mathrm{Sr}^{2+}$, and $\mathrm{Ba}^{2+}$-chelated crown ethers, calculations have been done with the LANL2DZ ECP (for metal ion alone). ${ }^{75}$ For uranium, Stuttgart/Dresden ECP of MWB $60{ }^{76}$ and the corresponding atomic natural orbital basis set ${ }^{77}$ have been used in all calculations. All electronic structure calculations have been done with the Gaussian program package $^{78}$.

\section{Supporting Information}

Cartesian coordinates of the optimized geometries, total electronic energies, zero-point vibrational energies (ZPVEs), ZPVE-corrected total energies, number of imaginary frequency values, and optimal geometry parameters obtained at different levels are given.

\section{Acknowledgment}

This research work did not receive any specific grant from public or private funding agencies. However, computational support provided at SDSU by DURIP Grant W911NF-10-1-0157 from the U.S. Department of Defense and by NSF CRIF Grant CHE-0947087 are gratefully acknowledged. One of the authors 
(VST) thank Prof. Andrew L. Cooksy (SDSU), Prof. Gabriel Merino (Center for Research and Advanced Studies of the National Polytechnic Institute, Mérida, Mexico) and Dr. Ramakrishnan Sethu (University of Illinois, UrbanaChampaign) for their interest in this work and useful discussions. Additional computational support provided to KT at VIT, Vellore, India, provided through a research grant (Project. No. YSS/2014/001019) from the Science and Engineering Research Board, Department of Science and Technology, New Delhi, Government of India, is also gratefully acknowledged.

\section{$7 \quad$ Keywords}

alkali metals, alkaline-earth metals, crown compounds, chelates, host-guest molecules, planar tetracoordinate carbon, uranyl $\left(\mathrm{UO}_{2}^{2+}\right)$ ion.

\section{TOC}

Novel flat crown ether molecules containing planar tetracoordinate carbon atoms (see picture 8) have been theoretically characterized using $\mathrm{Si}_{2} \mathrm{C}_{3}$ units as building blocks.

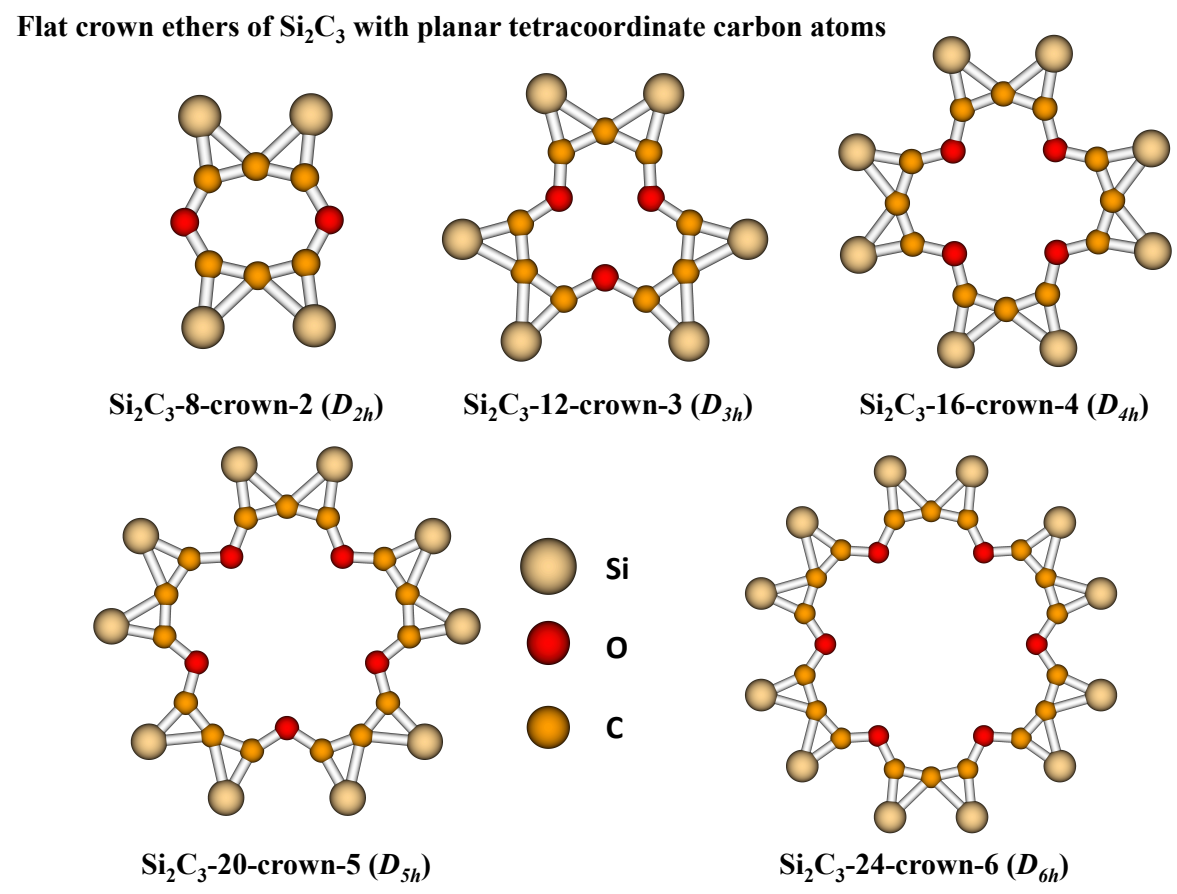




\section{Conflict of Interest}

The authors declare no conflict of interest. 


\section{References}

[1] H. J. Monkhorst. Activation energy for interconversion of enantiomers containing an asymmetric carbon atom without breaking bonds. Chem. Commun. (London), pages 1111-1112, 1968.

[2] Roald Hoffmann, Roger W. Alder, and Charles F. Wilcox. Planar tetracoordinate carbon. J. Am. Chem. Soc., 92:4992-4993, 1970.

[3] John B. Collins, James D. Dill, Eluvathingal D. Jemmis, Yitzhak Apeloig, Paul v. R. Schleyer, Rolf Seeger, and John A. Pople. Stabilization of planar tetracoordinate carbon. J. Am. Chem. Soc., 98:5419-5427, 1976.

[4] Reinhart Keese. Carbon flatland: Planar tetracoordinate carbon and fenestranes. Chem. Rev., 106:4787-4808, 2006.

[5] L. Radom and D. R. Rasmussen. The planar carbon story. Pure Appl. Chem., 70:1977, 1998.

[6] Gabriel Merino, Miguel A. Méndez-Rojas, Hiram I. Beltrán, Clemence Corminboeuf, Thomas Heine, and Alberto Vela. Theoretical analysis of the smallest carbon cluster containing a planar tetracoordinate carbon. $J$. Am. Chem. Soc., 126:16160-16169, 2004.

[7] Li-Ming Yang, Eric Ganz, Zhongfang Chen, Zhi-Xiang Wang, and Paul von Ragué Schleyer. Four decades of the chemistry of planar hypercoordinate compounds. Angew. Chem., Int. Ed., 54:9468-9501, 2015.

[8] B. Sateesh, A. Srinivas Reddy, and G. Narahari Sastry. Towards design of the smallest planar tetracoordinate carbon and boron systems. J. Comput. Chem., 28:335-343, 2007.

[9] Congjie Zhang, Pei Wang, Jinxia Liang, Wenhong Jia, and Zexing Cao. Theoretical study on a family of organic molecules with planar tetracoordinate carbon. J. Mol. Struct: THEOCHEM, 941(1):41 - 46, 2010.

[10] O. Yañez, A. Vásquez-Espinal, R. Pino-Rios, F. Ferraro, S. Pan, E. Osorio, G. Merino, and W. Tiznado. Exploiting electronic strategies to stabilize a planar tetracoordinate carbon in cyclic aromatic hydrocarbons. Chem. Commun., 53:12112-12115, 2017.

[11] Cherumuttathu H. Suresh and Gernot Frenking. Direct 13 metalcarbon bonding and planar tetracoordinated carbon in group 6 metallacyclobutadienes. Organometallics, 29(21):4766-4769, 2010.

[12] D. Roy, C. Corminboeuf, C. S. Wannere, R. B. King, and P. v. R. Schleyer. Planar tetracoordinate carbon atoms centered in bare four-membered rings of late transition metals. Inorg. Chem., 45:8902-8906, 2006. 
[13] Premaja R. Remya and Cherumuttathu H. Suresh. Planar tetracoordinate carbon in tungstenacyclobutadiene from alkyne metathesis and expanded structures. Dalton Trans., 45:1769-1778, 2016.

[14] Krishnan Thirumoorthy, Amir Karton, and Venkatesan S. Thimmakondu. From high-energy $\mathrm{c}_{7} \mathrm{~h}_{2}$ isomers with a planar tetracoordinate carbon atom to an experimentally known carbene. J. Phys. Chem. A, 122:9054-9064, 2018.

[15] Xi Li, Lai-Sheng Wang, Alexander I. Boldyrev, and Jack Simons. Tetracoordinated planar carbon in the $\mathrm{al}_{4} \mathrm{c}^{-}$anion. a combined photoelectron spectroscopy and ab initio study. J. Am. Chem. Soc., 121:6033-6038, 1999.

[16] Lai-Sheng Wang, Alexander I. Boldyrev, Xi Li, and Jack Simons. Experimental observation of pentaatomic tetracoordinate planar carboncontaining molecules. J. Am. Chem. Soc., 122:7681-7687, 2000.

[17] Xi Li, Hua-Jin Zhai, and Lai-Sheng Wang. Photoelectron spectroscopy of pentaatomic tetracoordinate planar carbon molecules: $\mathrm{Cal}_{3} \mathrm{si}$ and $\mathrm{cal}_{3} \mathrm{ge}$. Chem. Phys. Lett., 357:415 - 419, 2002.

[18] Xi Li, Hai-Feng Zhang, Lai-Sheng Wang, GrantD. Geske, and AlexanderI. Boldyrev. Pentaatomic tetracoordinate planar carbon, $\left[\mathrm{cal}_{4}\right]^{2-}:$ A new structural unit and its salt complexes. Angew. Chem., Int. Ed., 39:3630$3632,2000$.

[19] Jing Xu, Xinxing Zhang, Shuang Yu, Yi-hong Ding, and Kit H. Bowen. Identifying the hydrogenated planar tetracoordinate carbon: A combined experimental and theoretical study of $\mathrm{cal}_{4} \mathrm{~h}$ and $\mathrm{cal}_{4} \mathrm{~h}^{-}$. J. Phys. Chem. Lett., 8:2263-2267, 2017.

[20] Ernst-Ulrich Würthwein and Paul v. R. Schleyer. Planar tetracoordinate silicon. Angew. Chem., Int. Ed. Engl., 18:553-554, 1979.

[21] Yafei Li, Fengyu Li, Zhen Zhou, and Zhongfang Chen. Sic ${ }_{2}$ silagraphene and its one-dimensional derivatives: Where planar tetracoordinate silicon happens. J. Am. Chem. Soc., 133(4):900-908, 2011.

[22] Jin-Chang Guo, Chang-Qing Miao, and Guang-Ming Ren. Planar tetracoordinate si and ge in $\pi$-aromatic $\mathrm{x}_{3} \mathrm{cu}_{3}^{+}(\mathrm{x}=\mathrm{si}$, ge) cations. Comput. Theor. Chem., 1032:7-11, 2014.

[23] Jin-Chang Guo, Hui-Xia Wu, Guang-Ming Ren, Chang-Qing Miao, and Yong-Xia Li. $d_{3 h} \mathrm{x}_{3} \mathrm{li}_{3}^{+}(\mathrm{x}=\mathrm{c}$, si and ge): Superalkali cations containing three planar tetracoordinate $\mathrm{x}$ atoms. Comput. Theor. Chem., 1083:1-6, 2016.

[24] Venkatesan S. Thimmakondu and Krishnan Thirumoorthy. $\mathrm{Si}_{3} \mathrm{c}_{2} \mathrm{~h}_{2}$ isomers with a planar tetracoordinate carbon or silicon atom(s). Comput. Theor. Chem., 1157:40-46, 2019. 
[25] Fabian Ebner and Lutz Greb. Calix[4]pyrrole hydridosilicate: The elusive planar tetracoordinate silicon imparts striking stability to its anionic silicon hydride. J. Am. Chem. Soc., 140:17409-17412, 2018.

[26] Dirk Röttger and Gerhard Erker. Compounds containing planartetracoordinate carbon. Angew. Chem., Int. Ed. Engl., 36:812-827, 1997.

[27] F. Albert Cotton and Michelle Millar. The probable existence of a triple bond between two vanadium atoms. J. Am. Chem. Soc., 99(24):7886-7891, 1977.

[28] Osvaldo Yañez, Rodrigo Báez-Grez, Jorge Garza, Sudip Pan, Jorge Barroso, Alejandro Vásquez-Espinal, Gabriel Merino, and William Tiznado. Embedding a planar hypercoordinate carbon atom into a [4n+2] -system. ChemPhysChem, 21(2):145-148, 2020.

[29] Jin-Chang Guo, Lin-Yan Feng, Chuan Dong, and Hua-Jin Zhai. Planar pentacoordinate versus tetracoordinate carbons in ternary cbe $\mathrm{li}_{4}$ and $\mathrm{cbe}_{4} \mathrm{li}_{4}^{2-}$ clusters. J. Phys. Chem. A, 122(42):8370-8376, 2018. PMID: 30277775.

[30] Chao-Feng Zhang, Shao-Jin Han, Yan-Bo Wu, Hai-Gang Lu, and Gang Lu. Thermodynamic stability versus kinetic stability: Is the planar hexacoordinate carbon species $\mathrm{d}_{3 h} \mathrm{cn}_{3} \mathrm{mg}_{3}^{+}$viable? J. Phys. Chem. A, 118:3319-3325, 2014.

[31] Yan-Bo Wu, Yan Duan, Hai-Gang Lu, and Si-Dian Li. $\mathrm{Cal}_{2} \mathrm{be}_{3}^{2-}$ and its salt complex lical ${ }_{2} \mathrm{be}_{3}^{-}$: Anionic global minima with planar pentacoordinate carbon. J. Phys. Chem. A, 116(12):3290-3294, 2012. PMID: 22428936.

[32] Jin-Chang Guo, Lin-Yan Feng, Xiao-Ying Zhang, and Hua-Jin Zhai. Starlike cbe $_{5} \mathrm{au}_{5}^{+}$cluster: Planar pentacoordinate carbon, superalkali cation, and multifold ( $\pi$ and $\sigma$ ) aromaticity. J. Phys. Chem. A, 122(4):1138-1145, 2018. PMID: 29286669.

[33] Kai Exner and Paul von Ragué Schleyer. Planar hexacoordinate carbon: A viable possibility. Science, 290:1937-1940, 2000.

[34] Keigo Ito, Zhongfang Chen, Clémence Corminboeuf, Chaitannya S. Wannere, Xiu Hui Zhang, Qian Shu Li, and Paul v. R. Schleyer. Myriad planar hexacoordinate carbon molecules inviting synthesis. J. Am. Chem. Soc., 129:1510-1511, 2007.

[35] Boris B. Averkiev, Dmitry Yu. Zubarev, Lei-Ming Wang, Wei Huang, LaiSheng Wang, and Alexander I. Boldyrev. Carbon avoids hypercoordination in $\mathrm{cb}_{6}, \mathrm{cb}_{6}^{2-}$, and $\mathrm{c}_{2} \mathrm{~b}_{5}$ planar carbon-boron clusters. J. Am. Chem. Soc., 130:9248-9250, 2008.

[36] Yong Pei and Xiao Cheng Zeng. Probing the planar tetra-, penta-, and hexacoordinate carbon in carbonboron mixed clusters. J. Am. Chem. Soc., 130(8):2580-2592, 2008. PMID: 18237168. 
[37] Zhong-hua Cui, Valentin Vassilev-Galindo, José Luis Cabellos, Edison Osorio, Mesías Orozco, Sudip Pan, Yi-hong Ding, and Gabriel Merino. Planar pentacoordinate carbon atoms embedded in a metallocene framework. Chem. Commun., 53:138-141, 2017.

[38] Valentin Vassilev-Galindo, Sudip Pan, Kelling Donald J, and Gabriel Merino. Planar pentacoordinate carbons. Nat. Chem. Rev., 2:0114, 2018.

[39] Yu Wang, Feng Li, Yafei Li, and Zhongfang Chen. Semi-metallic be ${ }_{5} \mathrm{c}_{2}$ monolayer global minimum with quasi-planar pentacoordinate carbons and negative poissons ratio. Nat. Commun., 7:11488, 2016.

[40] Charles J. Pedersen. Cyclic polyethers and their complexes with metal salts. J. Am. Chem. Soc., 89(10):2495-2496, 1967.

[41] Donald J. Cram. Preorganization - from solvents to spherands. Angew. Chem., Int. Ed. Engl., 25(12):1039-1057, 1986.

[42] Jean-Marie Lehn. Supramolecular chemistry - scope and perspectives molecules, supermolecules, and molecular devices (nobel lecture). Angew. Chem., Int. Ed. Engl., 27(1):89-112, 1988.

[43] Michelle B. More, Douglas Ray, and P. B. Armentrout. Intrinsic affinities of alkali cations for 15-crown-5 and 18-crown-6: bond dissociation energies of gas-phase $\mathrm{m}^{+}$crown ether complexes. J. Am. Chem. Soc., 121(2):417-423, 1999.

[44] Eric D. Glendening, David Feller, and Mark A. Thompson. An ab initio investigation of the structure and alkali metal cation selectivity of 18-crown6. J. Am. Chem. Soc., 116(23):10657-10669, 1994.

[45] David Feller. Ab initio study of $\mathrm{m}^{+}$:18-crown-6 microsolvation. J. Phys. Chem. A, 101:2723-2731, 1997.

[46] Reed M. Izatt, Jerald S. Bradshaw, Steven A. Nielsen, John D. Lamb, James J. Christensen, and Debabrata Sen. Thermodynamic and kinetic data for cation-macrocycle interaction. Chem. Rev., 85(4):271-339, 1985.

[47] Krzysztof E. Krakowiak, Jerald S. Bradshaw, and Daria J. ZameckaKrakowiak. Synthesis of aza-crown ethers. Chem. Rev., 89(4):929-972, 1989 .

[48] Reed M. Izatt, Jerald S. Bradshaw, Krystyna Pawlak, Ronald L. Bruening, and Bryon J. Tarbet. Thermodynamic and kinetic data for macrocycle interaction with neutral molecules. Chem. Rev., 92(6):1261-1354, 1992.

[49] Reed M. Izatt, Krystyna. Pawlak, Jerald S. Bradshaw, and Ronald L. Bruening. Thermodynamic and kinetic data for macrocycle interaction with cations, anions, and neutral molecules. Chem. Rev., 95(7):2529-2586, 1995. 
[50] Matus Stredansky, Elia Turco, Zhijing Feng, Roberto Costantini, Giovanni Comelli, Alberto Verdini, Luca Floreano, Alberto Morgante, Carlo Dri, and Albano Cossaro. On-surface trapping of alkali atoms by crown ethers in ultra high vacuum. Nanoscale Adv., 1:1721-1725, 2019.

[51] Changho Yoo, Henry M. Dodge, and Alexander J. M. Miller. Cationcontrolled catalysis with crown ether-containing transition metal complexes. Chem. Commun., 55:5047-5059, 2019.

[52] R. Chiarizia, E. P. Horwitz, and M. L. Dietz. Acid dependency of the extraction of selected metal ions by a strontium. selective extraction chromatographic resin: Calculated versus experimental curves. Solvent Extr. Ion Exch., 10(2):337-361, 1992.

[53] Jay W. Grate, Robert Strebin, Jiri Janata, Oleg Egorov, and Jaromir Ruzicka. Automated analysis of radionuclides in nuclear waste: rapid determination of ${ }^{90}$ sr by sequential injection analysis. Anal. Chem., 68(2):333-340, 1996.

[54] Ilya A. Shkrob, Timothy W. Marin, and Mark L. Dietz. On the radiation stability of crown ethers in ionic liquids. J. Phys. Chem. B, 115(14):39033911, 2011. PMID: 21410191.

[55] Arijit Sengupta and Prasanta Kumar Mohapatra. Extraction of radiostrontium from nuclear waste solution using crown ethers in room temperature ionic liquids. Supramol. Chem., 24(11):771-778, 2012.

[56] Zhu Lin, Liu Zhongqun, Cheng Wenjun, and Cheng Shaojin. Removing cs from nuclear waste liquid by crown ether and heteropoly acid: Simulated tests. J. Radioanal. Nucl. Ch., 205(1):49-56, Apr 1996.

[57] K. S. Novoselov, A. K. Geim, S. V. Morozov, D. Jiang, Y. Zhang, S. V. Dubonos, I. V. Grigorieva, and A. A. Firsov. Electric field effect in atomically thin carbon films. Science, 306(5696):666-669, 2004.

[58] Luis Moreira, Beatriz M. Illescas, and Nazario Martín. Supramolecular complexation of carbon nanostructures by crown ethers. J. Org. Chem., 82(7):3347-3358, 2017. PMID: 28207255.

[59] Junjie Guo, Jaekwang Lee, Cristian I. Contescu, Nidia C. Gallego, Sokrates T. Pantelides, Stephen J. Pennycook, Bruce A. Moyer, and Matthew F. Chisholm. Crown ethers in graphene. Nature Communications, 5(1):5389, 2014.

[60] Alex Smolyanitsky, Eugene Paulechka, and Kenneth Kroenlein. Aqueous ion trapping and transport in graphene-embedded 18-crown-6 ether pores. ACS Nano, 12(7):6677-6684, 2018. PMID: 29940107. 
[61] Subin Sahu, Justin Elenewski, Christoph Rohmann, and Michael Zwolak. Optimal transport and colossal ionic mechano-conductance in graphene crown ethers. Science Advances, 5(7), 2019.

[62] Adaikkappan Periyakaruppan, Felix Kumar, Shubhashish Sarkar, Chidananda S. Sharma, and Govindarajan T. and Ramesh. Uranium induces oxidative stress in lung epithelial cells. Arch. Toxicol., 81:389-395, 2007.

[63] Xiaomei Wang, Xing Dai, Cen Shi, Jianmei Wan, Mark A. Silver, Linjuan Zhang, Lanhua Chen, Xuan Yi, Bizheng Chen, Duo Zhang, Kai Yang, Juan Diwu, Jianqiang Wang, Yujie Xu, Ruhong Zhou, Zhifang Chai, and Shuao Wang. A 3,2-hydroxypyridinone-based decorporation agent that removes uranium from bones in vivo. Nat. Commun., 10:2570, 2019.

[64] Isaac Bersuker. The Jahn-Teller Effect. Cambridge University Press, 2006.

[65] John P. Perdew, Kieron Burke, and Matthias Ernzerhof. Generalized gradient approximation made simple. Phys. Rev. Lett., 77:3865-3868, Oct 1996.

[66] Chengteh Lee, Weitao Yang, and Robert G. Parr. Development of the collesalvetti correlation-energy formula into a functional of the electron density. Phys. Rev. B, 37:785-789, Jan 1988.

[67] A. D. Becke. Density-functional exchange-energy approximation with correct asymptotic behavior. Phys. Rev. A, 38:3098-3100, Sep 1988.

[68] Axel D. Becke. Density-functional thermochemistry. iii. the role of exact exchange. J. Chem. Phys., 98:5648-5652, 1993.

[69] R. Krishnan, J. S. Binkley, R. Seeger, and J. A. Pople. Self-consistent molecular orbital methods. xx. a basis set for correlated wave functions. $J$. Chem. Phys., 72:650-654, 1980.

[70] Timothy Clark, Jayaraman Chandrasekhar, Günther W. Spitznagel, and Paul Von Ragué Schleyer. Efficient diffuse function-augmented basis sets for anion calculations. iii. the $3-21+\mathrm{g}$ basis set for first-row elements, li-f. J. Comput. Chem., 4:294-301, 1983.

[71] Stefan Grimme, Jens Antony, Stephan Ehrlich, and Helge Krieg. A consistent and accurate ab initio parametrization of density functional dispersion correction (dft-d) for the 94 elements h-pu. J. Chem. Phys., 132(15):154104, 2010 .

[72] Axel D. Becke and Erin R. Johnson. Exchange-hole dipole moment and the dispersion interaction. J. Chem. Phys., 122(15):154104, 2005.

[73] Stefan Grimme, Stephan Ehrlich, and Lars Goerigk. Effect of the damping function in dispersion corrected density functional theory. J. Comput. Chem., 32(7):1456-1465, 2011. 
[74] Jianmin Tao, John P. Perdew, Viktor N. Staroverov, and Gustavo E. Scuseria. Climbing the density functional ladder: Nonempirical meta-generalized gradient approximation designed for molecules and solids. Phys. Rev. Lett., 91:146401, Sep 2003.

[75] P. Jeffrey Hay and Willard R. Wadt. Ab initio effective core potentials for molecular calculations. potentials for $\mathrm{k}$ to au including the outermost core orbitals. J. Chem. Phys., 82(1):299-310, 1985.

[76] W. Küchle, M. Dolg, H. Stoll, and H. Preuss. Energy-adjusted pseudopotentials for the actinides. parameter sets and test calculations for thorium and thorium monoxide. J. Chem. Phys., 100(10):7535-7542, 1994.

[77] Xiaoyan Cao, Michael Dolg, and Hermann Stoll. Valence basis sets for relativistic energy-consistent small-core actinide pseudopotentials. J. Chem. Phys., 118(2):487-496, 2003.

[78] M. J. Frisch, G. W. Trucks, H. B. Schlegel, G. E. Scuseria, M. A. Robb, J. R. Cheeseman, G. Scalmani, V. Barone, G. A. Petersson, H. Nakatsuji, X. Li, M. Caricato, A. V. Marenich, J. Bloino, B. G. Janesko, R. Gomperts, B. Mennucci, H. P. Hratchian, J. V. Ortiz, A. F. Izmaylov, J. L. Sonnenberg, D. Williams-Young, F. Ding, F. Lipparini, F. Egidi, J. Goings, B. Peng, A. Petrone, T. Henderson, D. Ranasinghe, V. G. Zakrzewski, J. Gao, N. Rega, G. Zheng, W. Liang, M. Hada, M. Ehara, K. Toyota, R. Fukuda, J. Hasegawa, M. Ishida, T. Nakajima, Y. Honda, O. Kitao, H. Nakai, T. Vreven, K. Throssell, J. A. Montgomery, Jr., J. E. Peralta, F. Ogliaro, M. J. Bearpark, J. J. Heyd, E. N. Brothers, K. N. Kudin, V. N. Staroverov, T. A. Keith, R. Kobayashi, J. Normand, K. Raghavachari, A. P. Rendell, J. C. Burant, S. S. Iyengar, J. Tomasi, M. Cossi, J. M. Millam, M. Klene, C. Adamo, R. Cammi, J. W. Ochterski, R. L. Martin, K. Morokuma, O. Farkas, J. B. Foresman, and D. J. Fox. Gaussian 16 Revision B.01, 2016. Gaussian Inc. Wallingford CT. 